\title{
Characterization Electrochemical Duplex Steel UNS S31803 Welded By TIG Autogenous
}

\author{
Luís O.R. Barbosa ${ }^{1}$, Gláucio S. da Fonseca. ${ }^{2}$, Carlos R. Xavier. ${ }^{3}$, \\ Elivelton A. Ferreira ${ }^{4}$ \\ ${ }^{\text {I}}$ (Postgraduate Program in Metallurgical Engineering, PPGEM, Fluminense Federal University-UFF, Brazil) \\ ${ }^{2}$ (Professor at Federal Fluminense University - UFF, Brazil) \\ ${ }_{3}^{3}$ (Professor at University Center of Volta Redonda, Unifoa, Brazil) \\ ${ }^{4}$ (Professor at Fluminense Federal University-UFF, Brazil)
}

\begin{abstract}
The duplex steels are widely used in the area of oil exploration, both in structure and equipment. These steels provide excellent mechanical properties combined with excellent corrosion resistance. The welding of this material takes into account the loss of alloying elements, which are directly linked to the excellent properties of this material, this loss being compensated by the addition of metal during welding. In an autogenous weld, this addition of material to balance the loss is eliminated, and under these conditions, a study subjecting the duplex UNS S31803 steel to this process, a relationship between the microstructure of the weld region and an electrochemical characterization, will be shown that this loss does not interfere with the quality of the weld and the resistance of the material to corrosion.
\end{abstract}

Keywords: Duplex Stell, Autogenous Welding, Microstructure, Corrosion Resistance

\section{Introduction}

Duplex stainless steels (DSS) have been developed to meet the needs of the chemical and petrochemical industry, which require materials that are more resistant than ordinary stainless steels to both corrosive media and high temperatures and pressures. Are alloys containing about $18 \%$ to $30 \% \mathrm{Cr}, 1.5 \%$ to 4.5\% Mo and additions and forming elements and stabilizers of austenite, mainly nickel and nitrogen, in order to form a microstructure, at the temperature Composed of equal parts of ferrite and austenite. These steels have a high resistance to corrosion, a characteristic offered by the ferritic structure and high mechanical resistance and good weldability characteristic of the austenitic structure.

Chrome and manganese stabilize P.R.E. (Pitting resistance equivalent number), a factor that determines whether a stainless steel is classified as duplex or super duplex. Niobium increases the mechanical resistance of DSS. Nickel, manganese, copper and nitrogen are austenitizing elements, because they cause increase of austenitic phases in the DSS, leaving more pronounced properties of the austenitic phase. Moreover, manganese stabilizes the nitrogen solubility in DSS, while the copper corrosion resistance stabilizes, nitrogen, P.R.E. and both stabilize the hardness.

During welding operations, it is much difficult to obtain appropriate proportion of austenite and ferrite (50:50). Hsieh et al. [1] reported that the austenite contents lower than $25 \%$ are unacceptable for most industrial applications. Norsok standard [2] recommended that a minimum austenite content of 30\% is required to accept the welded joints in piping inspection. Thus, as a consequence of welding, it is difficult to maintain as properties of the material after welding, especially in relation to an autogenous weld.

With this study, we will show that, even with the impoverishment of chemical elements due to welding, UNS S31803 duplex stainless steel continues with good properties related to corrosion protection.

\section{Experimental Setup}

For this study two UNS S31803 steel plates with the following dimensions, 8 × 60 x $210(\mathrm{~mm})$ and the chemical composition shown in table (1) are used.

Table 1: Chemical composition

\begin{tabular}{cccccccccccc}
\hline UNS & SAF & $\% \mathbf{C}$ & $\% \mathbf{S i}$ & $\% \mathrm{Mn}$ & $\% \mathrm{P}$ & $\% \mathrm{~S}$ & $\% \mathrm{Cr}$ & $\% \mathrm{Ni}$ & $\% \mathrm{Mo}$ & $\% \mathrm{Cu}$ & $\% \mathbf{N}$ \\
\hline $\mathrm{S} 31803$ & 2205 & 0.023 & 0.32 & 1.85 & 0.03 & 0.001 & 22.50 & 5.30 & 2.90 & 0.03 & 0.166 \\
\hline
\end{tabular}

The welding process used was autogenous TIG and as a source of data and subsequent comparison, two different heat imput were used, one in each plate. The welding equipment used was the MigPulse 4001 DP Eutectic Castolin. The welds were made in a single pass and without addition metal deposition, a pure argon 
protection gas was used, at a flow rate of $15(\mathrm{~L} / \mathrm{min})$ to protect the melt pool. In all experiments, the electrode used a tungsten and thorium alloy (red tip) of 1/8 "diameter. Because it is a synergic equipment, it is necessary that some welding parameters be established, such as average current, frequency, electric arc length, electrode diameter and electrode tip angle. Already the value of the welding voltage is adjusted automatically by the welding machine.

According to the literature and in order to extrapolate the limits of the material, a weld with heat input was carried out within the stipulated values for this steel of $2.2(\mathrm{~kJ} / \mathrm{mm})$ and another with a value above the stipulated, of $2.8(\mathrm{~kJ} / \mathrm{Mm})$. These values were calculated using equation (1):

$$
H I=\frac{\eta V I}{S}
$$

Where HI is the heat input, $\eta$ is the yield factor considering as thermal losses, I - Current (A), V represents voltage $(\mathrm{V})$ and $\mathrm{S}$ is the welding speed $(\mathrm{mm} / \mathrm{min})$.

With all these parameters adjusted and calculated, it was possible to define two thermal inputs, being HI.1 - $2.2(\mathrm{~kJ} / \mathrm{mm})$, established as a medium contribution, and most commonly used for this type of process, and HI. $2-2.8(\mathrm{~kJ} / \mathrm{mm})$, this being a value that exceeds the limits established for this material.

Two samples were taken for microstructural characterization for each thermal input of the central region of the weld bead. All of them were sanded and polished, and the Behara was used to reveal the microstructure, with $80(\mathrm{ml})$ of distilled water and $20(\mathrm{ml})$ of hydrochloric acid. For every $100(\mathrm{ml})$ of the solution, $0.3(\mathrm{~g})$ of potassium metabisulfite was added. The samples were immersed in the solution for 15 seconds.

With Nikon optical microscope, five images of each region in each sample were made, a total of ten images divided by the region between the parental metal, the heat affected zone of low temperature (HAZ-LT), heat affected zone of high temperature (HAZ - HT) and weld zone. With the images and help of the free software Image $\mathbf{J}$, the present phases were quantified, as well as the measurement of the grain size in the thermally affected zone of high temperature.

For the electrochemical characterization, An EmStat3 potentiostat of the PalmSens brand was used. As reference electrode was used $(\mathrm{Ag} / \mathrm{AgCl})$, and a platinum counter electrode. An area of approximately 0.8 $\left(\mathrm{mm}^{2}\right)$ of the weld region and the base metal was contacted with an artificial solution of $3.5 \% \mathrm{NaCl}$, simulating sea conditions.

The test consisted of two steps: to measure the open circuit potential, thus obtaining the potential for corrosion, and later to use the technique called cyclic voltometry, in which a scan is made starting from $0.5(\mathrm{~V})$ below the measured corrosion potential And reaching a potential of 1.5 (V) above the corrosion potential. Scanning was performed using a data read speed of $1(\mathrm{mV} / \mathrm{s})$. All corrosion experiments were performed at room temperature.

In order to characterize the type of corrosion that occurred in the steel, an analysis was made in the SEM (Scanning Electron Microscope) model Carl Zeiss EVO MA 10, using the secondary electron technique.

\section{Results and discussions}

Using the Image $\mathbf{J}$ program, and with the images captured in the optical microscope, we obtained the following quantification of the phases present for the two solder energies, shown in Figures (1) and (2), and Tables (2) and (3).

Fig. 1: Microstructure - Heat Imput 1: (A) Parental Metal; (B) HAZ-LT; (C) HAZ-HT (D) Weld Zone.
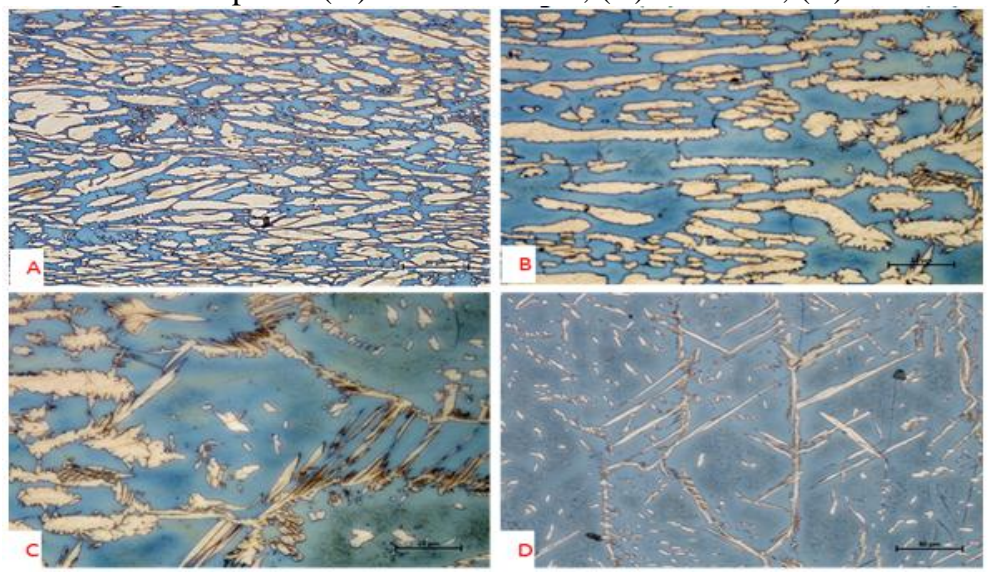
Table 2: Quantification of phases. Heat input 1.

\begin{tabular}{ccccc}
\hline Fase & PM & HAZ-LT & HAZ-HT & WZ \\
\hline Ferrite $\sigma$ & $58 \% \pm 3 \%$ & $69 \% \pm 2 \%$ & $73 \% \pm 2 \%$ & $89 \% \pm 1 \%$ \\
Austenite $\gamma$ & $42 \% \pm 3 \%$ & $31 \% \pm 2 \%$ & $27 \% \pm 2 \%$ & $11 \% \pm 1 \%$ \\
\hline
\end{tabular}

It is possible to note the difference between the percentage of phases as you move towards the welded area. Although the two phases, austenite (light phase) and ferrite (dark phase) continue to exist, we note the difference in their morphology, being present now the grain boundary austenite, Widmanstatten austenite, and intergranular austenite, mainly in the region of the weld. In the HAZ-LT region the attempt is made to distribute the phases, but the high cooling rate does not allow the phases to be distributed equally. This event is seen in all regions of the weld. It is also noted that the amount of the phases in the region of the weld is in line with the limits proposed by Norsok [2], obtaining $89 \%$ of Ferrite and $11 \%$ of Austenite.

Fig. 2: Microstructure - Heat Imput 2: (A) Parental Metal; (B) HAZ-LT; (C) HAZ-HT (D) Weld Zone.

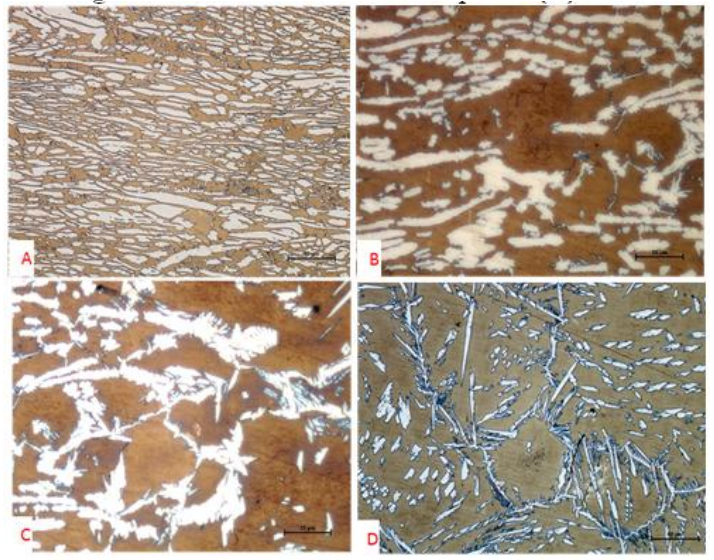

Table 3: Quantification of phases. Heat input 2.

\begin{tabular}{ccccc}
\hline Fase & PM & HAZ-LT & HAZ-HT & WZ \\
\hline Ferrita $\sigma$ & $66 \% \pm 3 \%$ & $70 \% \pm 3 \%$ & $71 \% \pm 1 \%$ & $80 \% \pm 2 \%$ \\
Austenita $~$ & $34 \% \pm 3 \%$ & $30 \% \pm 3 \%$ & $29 \% \pm 1 \%$ & $20 \% \pm 2 \%$ \\
\hline
\end{tabular}

As in the previous experiment, we can note the two phases ferrite (dark phase) and austenite (light phase) coexisting in all regions of the weld. The same morphologies are observed, containing austenite of grain, Widmanstatten austenite and intergranular austenite, mainly in the region of the weld. As a higher heat imput was used, the cooling rate was lower, so the material had more time for the microstructure to form, with grains relatively less than the previous sample.

The measurement of the grain size in the HAZ-HT was performed with the aid of the same software Imaje $\mathbf{J}$, which is the region considered critical for this type of weld. In table (4), the grain size of this region is shown.

Table 4: Grain Size HAZ-HT.

\begin{tabular}{lr}
\hline \multicolumn{2}{c}{ Grain Size } \\
\hline Heat Imput 1 & $24 \pm 2 \mu \mathrm{m}$ \\
Heat Imput 2 & $22 \pm 2 \mu \mathrm{m}$ \\
\hline
\end{tabular}

A slightly larger grain is noted in the region of the HAZ-HT with a lower heat imput. As the cooling rate is higher the grain does not have enough time to recompose its microstructure.

For the corrosion test, in which an electrochemical characterization was carried out, the sample was tested in two regions, one in the paretal metal and the other in the region of the weld. The test area of approximately $0.8 \mathrm{~mm}^{2}$ covered all the regions of the weld cited, and approximately 141 points were collected, which generated the polarization curves presented in the graphs (1) and (2) below. 
Graph 1: Polarization Curves to Heat Input 1. 1a-Parental Metal; 1b-Weld Zone.

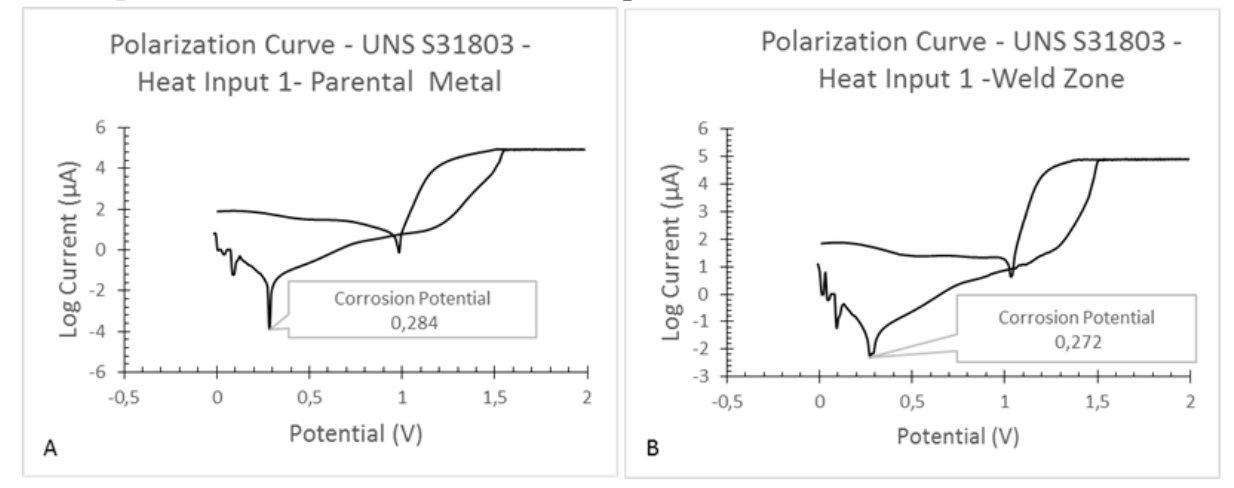

By the open circuit potential procedure, the $3.5 \% \mathrm{NaCl}$ solution was in contact with the metal in the regions shown. The value at which the stress stabilized indicates the corrosion potential of the region under study. It can be noted that the values indicated in graph (1a) and (1b) of the corrosion potentials are very close but in the parental metal it is subtly larger, indicating that in this region it would take longer to initiate corrosion. Disregarding the values of corrosion potential, we can notice the similarity between the curves, showing that regardless of the values, the two regions behave in the same way. In the anodic region of the graph, which compares the values above the corrosion potential, it is possible to notice an increase in current and soon afterwards the curve stabilizes, keeping the current practically stable while increasing the potential of the system. In this region is happening the passivation of the steel, that is, a thin layer of protection against corrosion is growing, while increasing the potential. From the moment the current increases again, this being an exponential increase, the corrosion process begins. Because it is a cyclic procedure, when it reaches a value 1.5 (V) above the corrosion potential, the process is reversed. This exponential increase of the current seen in the graph indicates a possible pitting corrosion, but to assert with certainty, only with the help of the microscope. It can be seen from the Figures (3a) and (3b), made by the SEM, that after the exponential growth of the current, there was no pitting corrosion. The type of corrosion evidenced by the images is of the type transgranular corrosion. In the cathodic region of the graph, that is, in the values below the corrosion potential, a small noise is noticed in the graph, this noise being attributed to a potentiostat failure.

Fig. 3: Transgranular Corrosion Heat Input 1. A - Paternal Metal; B - Weld Zone.

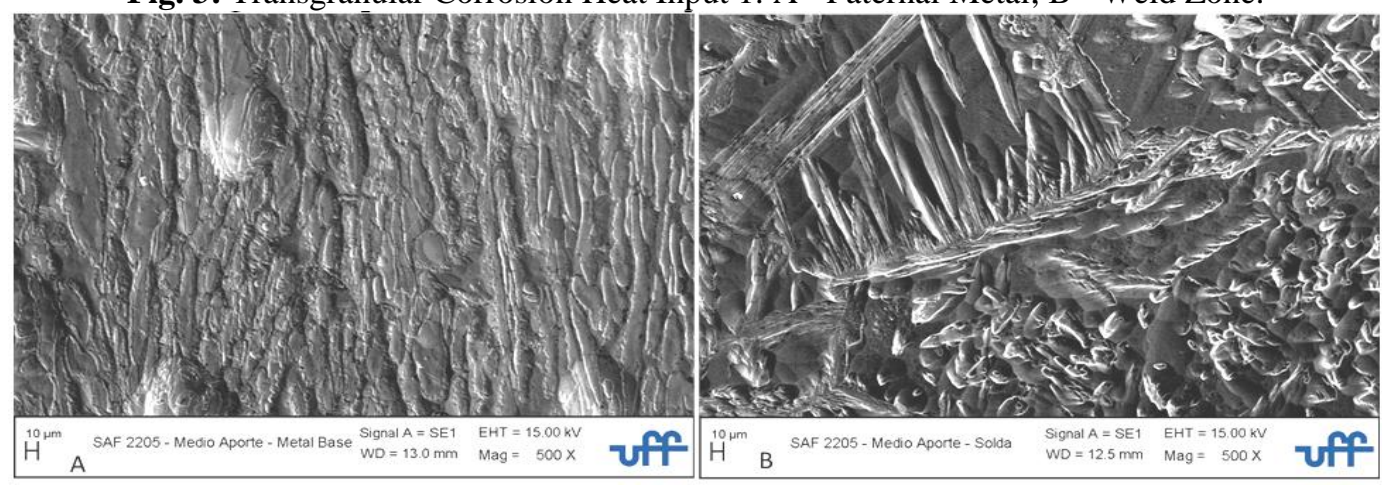

Graph 2: Polarization Curves to Heat Input 2. 1a-Parental Metal; 1b-Weld Zone.

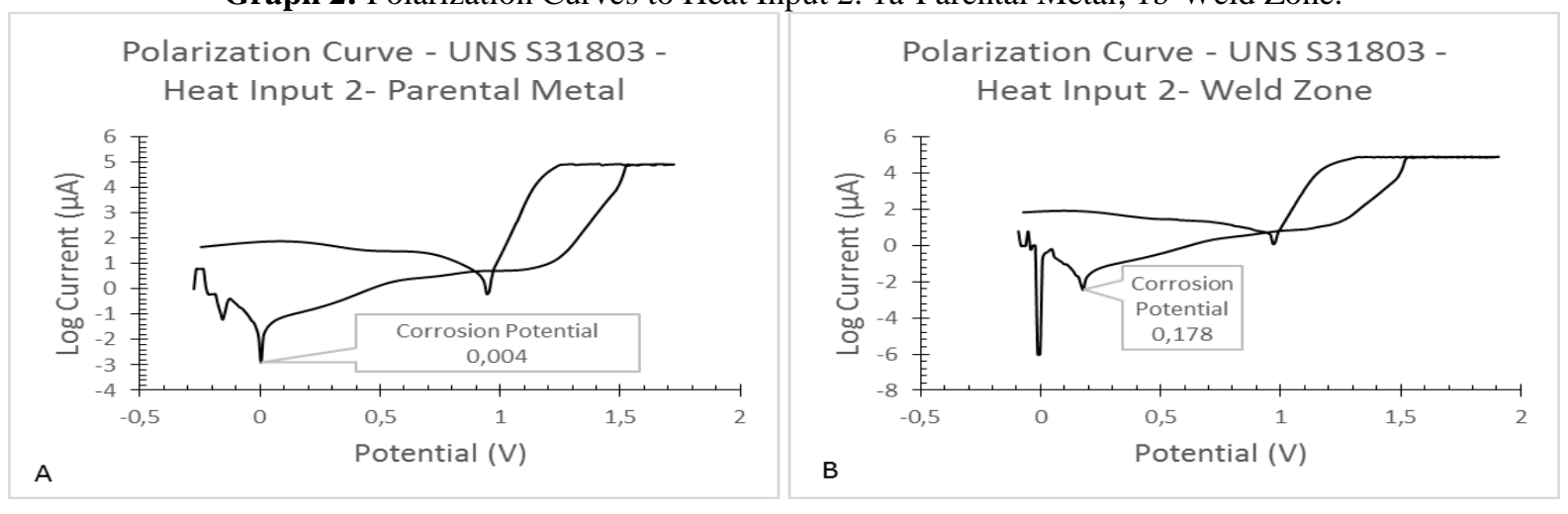


In the tests performed with a higher heatl input (HI-2), the similarity of the graph curves is noted. By the values of the corrosion potential shown in the graphs (2a) and (2b), it is possible to see that the parental metal obtained a lower value than in the region of the weld, however these values are variable and easily modified only by the conditions in which find the surfaces during the experiment. In this way, only the shape of the curves, which as in the previous experiment, obtained in the two tested regions an extensive region of passivation, until the moment of rupture of this protection film, generating an increase in the current and characterizing the corrosion. In the cathodic region of the graphs it is also possible to note some noises in the curves, these being attributed to an interference in the potentiostat.

In Figures (4a) and (4b), obtained by the SEM, we can show the same type of corrosion that occurred previously, that is, trangranular corrosion.

Fig.4: Transgranular Corrosion Heat Input 2. A - Paternal Metal; B - Weld Zone.

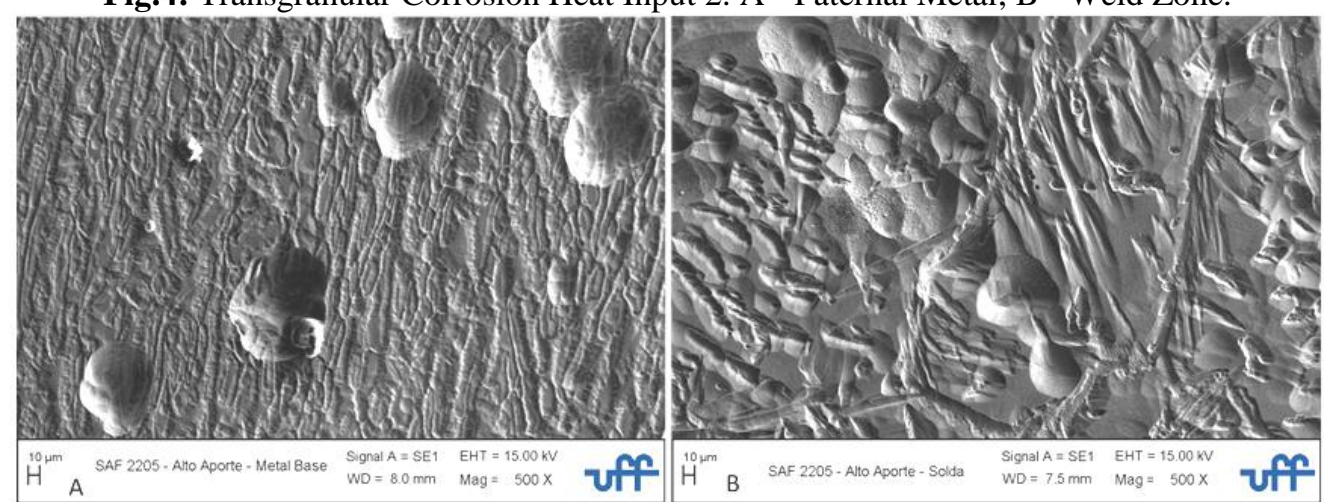

\section{Conclusions}

The autogenous TIG welding carried out in the experiments discharged the duplex stainless steel UNS S31803. As regards the microstructure characterization, the amount of ferrite and austenite present in the molten zone was below the industrially acceptable minimum limit in its applications. It was not noticed the appearance of intermetallic phases, which damage the mechanical characteristics of the metal. Although the distribution of the present phases were below the acceptable level, the autogenous TIG weld, without addition of material to compensate the loss of alloying elements that provide a high resistance to corrosion, did not compromise its efficiency in this respect.

The occurrence of pitting corrosion was not noted in any of the experiments, even under the extreme conditions in which the steels were tested. The corrosion observed was of the trangranular type, but there was no evidence of cracks, which is a characteristic in this type of corrosion.

\section{Acknowledgements}

I would like to thank Laboratory Technician Flumiense Federal University, Célio de Jesus Marcelo for their partnership and teachings, making the results possible.

\section{References}

[1]. Hsieh RI, Liou HY, Pan YT. Effects of cooling time and alloying elements on the microstructure of the Gleeble-simulated heat affected zone of 22\% Cr duplex stainless steels. J Mater Sci Perform 2001;10(5):526-36.

[2]. Norsok Standard M601-94. Welding and inspection of piping. Lysaker, Norway: Standards Norway; 2004.

[3]. ASM HANDBOOK. Metallography and Microestructures. V. 9, p. 228-293.

[4]. AUDOUARD, J. P. Corrosion performance of duplex stainless steels for kraft pulp digesters application. In: Conference Duplex Stainless Steel 97. Proceedings. The Netherlands, 1997. p. 565-72.

[5]. BAESLACK, W; LIPPOLD, J.C. Phase transformation behavior in duplex stainless steels weldments. Metal construction. v.20, n.1, p.26R-31R, 1988.

[6]. DELBLANC BAUER, A.; LUNDELL, U.; ERIKSSON, H. Presentation of corrosion data for end-users. In: Conference Duplex Stainless Steel 97. Proceedings. The Netherlands, 1997. p. 573-83.

[7]. HEMMER, H.; GRONG. A process model for the heat-affected zone microstructure evolution in duplex stainless steel weldments. Part 1. The model. Metallurgical and Material Transactions A, v.30A, p.2915-2929, Nov. 1999.

[8]. SEDRIKS, A. J. Corrosion of stainless steel. John Wiley. New York, 1996. Cap 1.

[9]. POTGIETER, J. H.; CORTIE, M. B. Determination of the microstructure and alloy element distribution in experimental duplex stainless steels. Materials characterization v.26 1991 p. 155-165.

[10]. HOCHMAN, J.; STAEHLE, R. W. Stress corrosion cracking and hydrogen enbrittement of iron base alloys. NACE, Houston, Texas, In press, 1969.

[11]. ISAACS, H. S. et al. Advances in localized corrosion, NACE. Houston, Texas, 1990. 